\title{
İneklerde Tohumlama Sonrası Uygulanan Lesirelin Asetat (GnRH Analogu)'ın Gebelik Oranları Üzerine Etkisi
}

\author{
Coşkun CAN ${ }^{1}$, Hamit YILDIZ ${ }^{2}$ \\ ${ }^{1}$ Gıda Tarım ve Hayvancılık Bakanlığı Muş il Müdürlüğü, Türkiye. \\ ${ }^{2}$ Fırat Üniversitesi Veteriner Fakültesi Doğum ve Jinekoloji Anabilim Dalı, Elazığ, Türkiye.
}

Geliş Tarihi: 18.04.2018

Kabul Tarihi: 07.06.2018

\begin{abstract}
Özet: Bu çalışmada, ineklere suni tohumlama sonrası farklı yollardan lesirelin asetat enjeksiyonlarının gebelik oranları üzerindeki etkisi araştırıldı. Materyal olarak postpartum 50-120. günler arasında kendiliğinden östrüse gelen, düzenli aralıklarla seksüel siklus gösteren ve bu süreçte herhangi bir klinik bozukluk göstermeyen farklı ırk ve yaştan 180 inek kullanıldı. Çalışmada kullanılan inekler rastgele 4 gruba ayrıldı. A grubunda bulunan $(n=50)$ hayvanlara suni tohumlamadan hemen sonra $50 \mu \mathrm{g}$ lesirelin asetat, B grubu $(n=40)$, hayvanlara $2 \mathrm{ml}$ serum fizyolojik üst epidural boşluğa uygulandı. C grubu $(n=50)$, hayvanlara suni tohumlamadan hemen sonra kas içi $50 \mu \mathrm{g}$ lesirelin asetat, $D$ grubuna $(n=40), 2 \mathrm{ml}$ serum fizyolojik gene kas içi olarak enjekte edildi. Lesirelin asetatın üst epidural boşluğa uygulandığı A ve B grubunda hayvanların gebelik oranları (sırasıyla \% 64, \% 45) arasında farklılı̆ın istatistiki açıdan anlamlı olduğu ( $\mathrm{P}<0.05)$ görüldü. Kas içi uygulama yapılan $C$ ve D grubunda gebelik oranları (sırasıyla \% 60, \% 52,5) yönüyle arasındaki farkın anlamlı olmadığı ( $P>0.05$ ) belirlendi. Ayrıca, üst epidural ve kas içi GnRH uygulanan gruplar arasında da istatistiki bir farkın $(P>0.05)$ olmadığı tespit edildi. Sonuç olarak, yapılan çalışmada kendiliğinden östrüse gelen ineklere tohumlama ile birlikte epidural yolla uygulanan GnRH enjeksiyonlarının gebelik oranlarını artırmada faydalı olacağı kanaatine varıldı.
\end{abstract}

Anahtar Kelimeler: Inek, Lesirelin asetat, Epidural uygulama, Gebelik oranı.

\section{Effect on Pregnancy Rates of Injected Lecirelin Acetate (GnRH analogue) after Insemination in the}

\section{Cows}

\begin{abstract}
In the present study the effects of lecirelin acetate injections applied in different ways after artificial insemination on the pregnancy rate of cows were investigated. As a material, 180 cows showing the spontaneous oestrus between 50 120 days after parturation and having the sexual cycle at regular intervals and showing no clinical disorders during the treatment process were used. The cows were randomly divided into 4 groups as A, B, C and D. In the group A ( $n=50) 50 \mu g$ lecirelin acetate was injected to the sacrococcygeal epidural space of the animals immediately after the artificial insemination. The animals in the group $B(n=40)$ were injected with $2 \mathrm{ml}$ physiological saline solution by the same route applied to the animals in the group $A$. The animals in the group $C(n=50)$ were injected with $50 \mu g$ lecirelin acetate intramuscularly immediately after the artificial insemination. The animals in the group $D(n=40)$ were injected with $2 \mathrm{ml}$ physiological saline solution by the same route applied to the animals in the group C. Statistically significant in difference ( $P$ $<0.05)$ were observed between the pregnancy rates of groups $A$ and $B(64 \%)$ and $(45 \%)$. It was detected that there was no significant difference $(P>0.05)$ in the pregnancy rates of the groups $C$ and $D(60 \%$ and $52,5 \%$, respectively). In addition, no significant difference $(P>0.05)$ was observed between the group A (applied epidural $G n R H$ ) and $C$ (applied intramuscular $\mathrm{GnRH}$ ). As a result, it was concluded that either intramuscular or epidural administration of Lecirelin Acetate to cows showing spontaneous oestrus can be used after artificial insemination to increase the pregnancy rates.

Keywords: Cow, Lecirelin acetate, Epidural treatment, Pregnancy rate.
\end{abstract}

\section{Giriş}

$\mathrm{GnRH}$, hipotalamustaki, arkuatik nükleusta bulunan eminensiya mediyalis'e taşınarak burada depo edilen bir nörohormondur (Padula, 2005; Scheiber ve Liu 2014; Singh ve ark., 2008). Adenohipofizde gonadotrop hücrelerin yüzeyinde bulunan $G$ proteini ile eşlenmiş reseptörüne bağlanarak, hücre içi bir seri fizyolojik reaksiyonu başlatıp, bu hücrelerden folikül uyarıcı hormon (FSH) ve lüteinleştirici hormonun (LH) sentezini ve salınmasını başlatır. Böylece, hipotalamus-hipofiz- gonat eksenine dolaylı etki ederek, gametogenezis ve steroidogenezisin düzenlenmesinde önemli görevler üstlenir (Padula, 2005; Scheiber ve Liu 2014). Lesirelin'in doğal GnRH'dan farkı; dekapeptit değil, nonapeptit olması ve yapısının 10 . pozisyonunda glisin yerine yüksek lipofilik etilamino grubunun yer almış olmasıdır. Bu yapı değişikliği özellikle hipofizyal reseptörlerin seçiciliğini artırarak, FSH ve LH seviyelerinin yükselmesini ve doğal hormon ile 90 dakika olan sürenin 240 dakikaya 
kadar uzamasını sağlar (Millar, 2005; Schneider ve ark., 2006).

GnRH agonistleri, damar içi (Padula, 2005; Scheiber ve Liu 2014), deri altı (Herbert ve Trigg 2005; Padula, 2005; Scheiber ve Liu 2014 ), vajina içi (Padula, 2005), burun içi (Padula, 2005; Scheiber ve Liu 2014), uterus içi ( Bas ve ark., 2012), dilaltı (Scheiber ve Liu 2014), kas içi (Annalisa ve ark., 2011; Herbert ve Trigg 2005; Scheiber ve Liu 2014 ) ve epidural boşluğa (Annalisa ve ark., 2011; Rizzo ve ark., 2011; Üstün, 2011) uygulanmak suretiyle klinikte kullanılmaktadır. Son zamanlarda GnRH agonistlerinin epidural yolla uygulanmasının kas içi uygulamaya göre iyi bir alternatif yol olduğu bildirilmiştir (Annalisa ve ark., 2011; Rizzo ve ark., 2009). GnRH agonistlerinin epidural yolla uygulanmasının avantaj ve dezavantajları bulunmaktadır. Bazı araştırmacılar, epidural boşluğa uygulanan $\mathrm{GnRH}$ agonistlerinin daha hızlı ve güçlü etki gösterdiğini savunmaktadırlar. İneklerde ovaryumların innervasyonu, direkt olarak sempatik sinirlerle sağlanmaktadır. Epidural boşluğa verilen adrenerjik aktiviteye sahip ilaçlar, doğrudan kendi reseptörlerini uyararak muhtemel etkinin oluşmasını sağlamaktadırlar (Annalisa ve ark., 2011; Millar, 2005). Koyun (Dolan ve ark.,2003) ve sığırlarda (Millar, 2005) omurilik üzerinde yapılan çalışmalarda $\mathrm{GnRH}$ reseptörlerinin bulunduğu tespit edilmiştir. Lesirelinin kimyasal yapısında 10. pozisyonda glisin yerine etilamino grubunun bulunması molekülün lipofilik özellikte olmasını ve molekülün epidural boşluk ve meninksleri geçerek omurilikte daha etkin bir şekilde ulaşmasını sağlamaktadır (Annalisa ve ark., 2011; Millar, 2005). Lesirelin, omurilikte bulunan $\mathrm{GnRH}$ reseptörlerinde hücre içi kalsiyum girişini arttırır. Ovaryumları uyaran sempatik sinir sonlarında hücre içi kalsiyum girişinin artması ile norepinefrin salgılanarak, GnRH'nın ovaryum üzerine olan etkisi ortaya çıkmaktadır. Sempatik innervasyon, foliküler matürasyon, steroit salınımı ve ovulasyonda önemli rol oynamaktadır (Rizzo ve ark., 2011). Ayrıca, norepinefrin folikül duvarının kontraktilitesini arttırarak ovulasyon sonrası korpus hemorajikum ve korpus lüteumun oluşmasını desteklemektedir (Rizzo ve ark., 2011; Singh ve ark., 2008).

$\mathrm{Bu}$ çalışmanın amacı, postpartum 50-120 günler arasında bulunan ineklere suni tohumlamadan hemen sonra üst epidural ve kas içi yolla yapılan $50 \mu \mathrm{g}$ lesirelin asetat uygulamalarının gebelik oranları üzerine etkisinin araştırılmasıdır.

\section{Materyal ve Metot}

Sunulan çalışmada, yaşları 3-8 arasında değişen 180 adet inek kullanıldı. Çalışmada materyal olarak, aile tipi işletmelerden hayvan ırkı gözetilmeksizin (52 adet Holştayn melezi, 56 adet Montafon ve 72 adet Simental melezi), postpartum 50-120. günler arasında kendiliğinden östrüse gelmiş ineklerden seçildi. Çalışmaya alınan inekler, düzenli aralıklarla seksüel siklus gösteren ve reprodüktif açıdan herhangi bir klinik bozukluğu bulunmayan hayvanlar arasından seçildi. Inekler rastgele 4 gruba ayrıldı. A grubunda bulunan $(n=50)$ ineklere suni tohumlamadan hemen sonra (ilk $10 \mathrm{dk}$ içinde) üst epidural yolla $50 \mu \mathrm{g}$ lesirelin asetat içeren preparattan (Dalmarelin, $10 \mathrm{ml}, 25 \mu \mathrm{g} / \mathrm{ml}$, VETAŞ) 2 $\mathrm{ml}$, B grubu $(\mathrm{n}=40)$; ineklere suni tohumlamadan hemen sonra $2 \mathrm{ml}$ serum fizyolojik üst epidural yolla uygulandı. Yine suni tohumlamadan hemen sonra $C$ grubunda $(n=50)$, ineklere $50 \mu \mathrm{g}$ lesirelin asetat içeren preparattan $2 \mathrm{ml}$ kas içi, D grubuna $(\mathrm{n}=40)$ ise; $2 \mathrm{ml}$ serum fizyolojik kas içi olarak enjekte edildi. İneklerede östrüsün tespiti, hayvan sahiplerinden alınan anamnezin yanı sıra, vulvada ödem ve servikal mukus akıntısının gözlenmesi, hayvanların üzerine atlama veya diğer hayvanların atlamasına izin verme, rektal muayenede uterusta tonosite artışı ve ovaryumlarında büyük Graaf folikülü varlığı esas alınarak yapıldı. Östrüs tespit edildikten sonra ineklerde tohumlama, rekto-vajinal yöntemle yapıldı. Gebelik muayeneleri suni tohumlama sonrası 30-35. günlerde B model realtime ultrasonografi cihazı (100 Falco, Pie Medical Netherlands) ile $7,5 \mathrm{MHz}$ lineer prob kullanılarak yapıldı. Gebelik sonuçlarının istatistiksel değerlendirilmeleri SPSS 21,0 bilgisayar programında Ki-kare testi kullanılarak yapıldı (Hayran ve Özdemir, 1996).

\section{Bulgular}

Tohumlamadan hemen sonra epidural ve kas içi GnRH uygulaması yapılan A ve $C$ grupları ile kontrol olarak kullanılan $B$ ve $D$ gruplarının hayvan sayıları ve gebelik oranları Tablo 1'de verilmiştir.

Tablo 1: Epidural ve kas içi yolla GnRH uygulanan ineklerde gebelik oranları.

\begin{tabular}{lccc}
\hline & \multicolumn{3}{c}{ Gebelik oranları (\%) } \\
\hline \multirow{4}{*}{ Epidural } & A grubu & B grubu & P \\
\cline { 2 - 3 } & $64^{\text {a }}$ & $45^{\text {b }}$ & 0,05 \\
\hline \multicolumn{3}{c}{ Gebelik oranları (\%) } \\
\hline \multirow{3}{*}{ Kas içi } & C grubu & D grubu \\
\cline { 2 - 4 } & 60 & 52,5 & - \\
\hline
\end{tabular}

a,b: Aynı satırda farklı harf taşıyan değerler arasındaki fark önemli $(P<0,05)$.

Buna göre, gebelik oranları yönüyle incelendiğinde $A$ ve $B$ grupları arasında istatistiksel olarak farklıı̆̆ın anlamlı bulunduğu $(P<0.05)$, kas içi 
uygulama yapılan C ve D grupları arasında ise anlamlı bir farklılığın olmadığı $(P>0.05)$ belirlendi. Ayrıca, epidural (A grubu) ve kas içi (C grubu) $\mathrm{GnRH}$ uygulanan gruplar arasında istatistiksel olarak bir farklılığın ( $P>0.05$ ) bulunmadığı saptanmıştır.

\section{Tartışma ve Sonuç}

Tohumlamadan hemen sonra değişik GnRH analoglarının farklı dozlarda uygulandığı çalışmalarda birbirinden farklı gebelik oranları elde edildiği bildirilmektedir (Anjum ve ark., 2009; Gumen ve ark., 2011; Kaim ve ark., 2003; Martin ve ark., 2005; Nakao ve ark., 1983; Perry ve Perry, 2009; Şekerden ve ark., 2009).

Bazı araştırmalarda GnRH uygulamalarının gebelik oranlarını artırdığı ileri sürülmektedir (Anjum ve ark., 2009; Kaim ve ark., 2003; Nakao ve ark., 1983; Lee ve ark., 1983; Lee ve ark., 1985; Stevenson ve ark., 1984). Anjum ve ark. (2009) repeat breeder ineklere tohumlama sonrası $50 \mu \mathrm{g}$ lesirelin asetatı kas içi uygulamalarında \% 68,75, kontrol grubunda \% 37,5 gebelik oranı elde ettiğini bildirmektedir. Başka bir çalışmada (Şekerden ve ark., 2009), tohumlama sonrası lesirelin asetat uygulanan 21 hayvandan 13'ünün gebe kaldığını ve uygulamanın gebelik oranlarını artırdığını belirtilmektedir. Bu sonuçların aksine tohumlama sonrası GnRH uygulamalarının gebelik oranları üzerinde herhangi bir etkisinin olmadığını bildiren araştırıcılar da vardır (Chenault, 1990; Gumen ve ark., 2011; Lopez-Gatius ve ark., 2006; Mee ve ark., 1990; Perry ve Perry, 2009). Sunulan çalışmada kullandığımız GnRH analoğu olan lesirelin asetat ile ilgili araştırmalarda ise, tohumlama sonrası 5 . günde lesirelin asetat uygulamalarında (Kaçar ve ark., 2007) ve postpartum 60-80. günler arasında tohumlama sonrası lesirelin asetat uygulanan hayvanlarda (Martin ve ark., 2005) gebelik oranı ile kontrol grubu arasında istatistiksel anlamda bir farkın olmadığı bildirilmektedir. Yapılan bu çalışmada, ineklere doğum sonrası 50-120. günler arasında suni tohumlama ile birlikte kas içi $50 \mu \mathrm{g}$ lesirelin asetat uygulamalarında gebelik oranının \% 60 , kontrol grubunda \% 52,5 olduğu ve gruplar arasında istatistiksel olarak anlamlı bir farkın olmadığı belirlendi. Çalışmada elde edilen bu gebelik oranları bazı araştırıcıların (Gumen ve ark., 2011; Lopez-Gatius ve ark., 2006; Martin ve ark., 2005; Perry ve Perry, 2009) bulguları ile paralellik gösterirken, bazı araştırıcıların sonuçları ile uyumlu olmadığı (Kaim ve ark., 2003; Lopez-Gatius ve ark., 2006; Stevenson ve ark., 1984) tespit edildi. Sonuçlar arasındaki farklılık, bazı araştırıcıların (Momcilovic ve ark., 1998; Stevenson ve ark., 1984) belirttiği gibi ineklerin vücut kondisyonları, östrüsün tespiti, spermanın çözdürülmesi ve suni tohumlama uygulamaları gibi farklılıklardan kaynaklanabiliceği şüphesi uynamıştır.

Yapılan çalışmaların çoğunda (Anjum ve ark., 2009; Annalisa ve ark., 2011; Rizzo ve ark., 2009; Rizzo ve ark., 2011; Şekerden ve ark., 2009) GnRH uygulaması kas içi yolla yapılmıştır. Foliküler kistli hayvanlarda epidural GnRH'ın uygulamasının kas içi uygulamaya göre daha iyi sonuç verdiği ileri sürülmüştür (Annalisa ve ark., 2011). Postpartum $60-120$. günler arasında bulunan ve foliküler kist şekillenen hayvanlara üst epidural ve kas içi yolla 50 $\mu \mathrm{g}$ lesirelin asetat uygulamalarında, hayvanların östrüse gelme oranlarının (sırasıyla, \%75 ve \%57) ve gebelik oranlarının (sırasıyla, \% 93 ve \% 76) kas içi uygulamaya göre daha yüksek olduğu tespit edilmiştir (Annalisa ve ark., 2011). Benzeri şekilde yapılan başka bir çalışmada (Robbe ve ark., 2002) postpartum ilk 60 gün içinde bulunan ve foliküler kist proplemi olan ineklere epidural ve kas içi yolla $50 \mu \mathrm{g}$ lesirelin asetat uygulamalarında östrüse gelme oranları sırasıyla, \% 81,2, \%59,4 ve gebelik oranları sırasıyla, $\% 75, \% 53,1$ olduğunu ve epidural enjeksiyonlarda daha iyi netice alındığı bildirilmektedir. Sunulan çalışmada tohumlama ile birlikte lesirelin asetatın epidural (Grup A, \% 64) ve kas içi (Grup C, \% 60) yolla uygulanması arasında gebelik oranları yönüyle bir farkın olmadığı tespit edildi. Elde edilen sonuçların araştırıcıların bulgularından farklı olmasının nedeni GnRH'ın farklı olgularda kullanılmasından kaynaklanabilir.

Epidural olarak uygulanan GnRH'nın bu etkisine ilişkin değişik görüşler bulunmaktadır. Dolan ve ark. (2003) epidural boşluğa uygulanan GnRH serebrospinal sıvı aracılığı ile merkezi sinir sistemine ve buradan hipotalamus ve hipofiz bezine ulaştığını belirtmektedirler. Epidural uygulanan GnRH kan akımına karışarak beyine ulaşır, ancak omurilik ve ovaryum üzerinde oluşturduğu direk bir lokal mekanizma ile folikülün çözülmesine yol açtığı ileri sürülmektedir (Annalisa ve ark., 2011). Başka bir çalışmada (Gajewski ve ark., 2006) lesirelin, omurilikte bulunan $\mathrm{GnRH}$ reseptörlerinde hücre içi kalsiyum girişini artırdığı bildirilmektedir. Ovaryumları uyaran sempatik sinir sonlarında hücre içi kalsiyum girişinin artması ile norepinefrin salgılanmaktadır. Salgılanan norepinefrin, foliküllerin duvarında kontraktilitenin artmasını, ovulasyon sonrası granülasyon dokusunun düzenlenmesi ve luteal dokunun gelişmesini sağlamaktadır (Espey, 1978; Rizzo ve ark., 2009). Epidural yolla uygulanan GnRH'ın ovulasyon üzerindeki etki mekanizmasına ilişkin araştırıcıların (Annalisa ve ark., 2011; Dolan ve ark., 2003; Gajewski ve ark., 2006) ortaya koyduğu düşüncelere katılmakla beraber bu konu ile ilgili olarak etki 
mekanizmasını ortaya koyan ayrıntılı farmakodinamik ve farmakokinetik araştırmaların yapılmasında fayda bulunmaktadır.

Araştırıcılar (Annalisa ve ark., 2011; Rizzo ve ark., 2009; Rizzo ve ark., 2011) foliküler kistli ineklere üst epidural yolla lesirelin asetat kullanırken, kontrol olarak kullanılan hayvanlara epidural olarak serum fizyolojik kullandığıda hayvanların hiçbirinin kızgınlığa gelmediğini belirtmektedirler. Sunulan çalışmada, tohumlama ile birlikte epidural $50 \mu \mathrm{g}$ lesirelin asetat enjekte ettiğimiz grupta gebelik oranı \% 64, kontrol grubunda ise bu oran \% 45 olarak belirlendi. Her iki grup arasında istatistiki olarak farklılığın olduğu $(P<0.05)$ tespit edildi.

Sonuç olarak, kendiliğinden kızgınlığa gelen hayvanlara tohumlamadan hemen sonra üst epidural yolla uygulanan $\mathrm{GnRH}$ enjeksiyonlarının gebelik oranlarını artırmada faydalı olduğu kanaatine varıldı.

\section{Kaynaklar}

Anjum IA, Usmani RH, Tunio MT, Abro SH, 2009: Improvement of conception rate in crossbred cattle by using $\mathrm{GnRH}$ analogue therapy. Pakistan Vet. J, 29, 93-94.

Annalisa R, Debora C, Maddalena M, Giuseppe $M$, Massimo S, Luigi SR, 2011: Epidural vs intramuscular administration of lecirelin, a GnRH analogue, for the resolution of follicular cysts in dairy cows. Anim Reprod Sci, 126, 19-22.

Bas S, Pinto CG, Day ML, Schuenemann GM, 2012: Effect of intrauterine administration of gonadotropin releasing hormone on serum $\mathrm{LH}$ concentrations in lactating dairy cows. Theriogenology, 78, 1390-1397.

Chenault JR, 1990: Effect of fertirelin acetate or buserelin on conception rate at first or second insemination in lactating dairy cows. J Dairy Sci, 73, 633-638.

Dolan S, Evans NP, Richter TA, Nolan AM, 2003: Expression of gonadotropin-releasing hormone and gonadotropin-releasing hormone receptor in sheep spinal cord. Neurosci Lett, 346, 120-122.

Espey LL, 1978: Ovarian contractility and its relationship to ovulation: a review. Biol Reprod, 19, 540-551.

Gajewski Z, Thun R, Faundez R, Pawlinski B, 2006: The influence of $\alpha$-adrenergic receptors stimulator and blockers and beta-blocker on the ovary and endocrinological activity in heifers during ovulation. J Physiol Pharmacol, 57(8), 173-188.

Gumen A, Keskin A, Yilmazbas-Mecitoglu G, Karakaya E, Cevik S, Balci F, 2011: Effects of GnRH, PGF2 $\alpha$ and oxytocin treatmentson conception rate at the time of artificial inseminationin lactating dairy cows. Czech J Anim Sci, 56(6), 279-283.

Hayran M, Özdemir O, 1996: Bilgisayar, istatistik ve tıp. 2. Baskı: Medikomat hekimler yayın birliği, Ankara, Türkiye.
Herbert CA, Trigg TE, 2005: Application of GnRH in the control and management of fertility in female animals. Anim Reprod Sci, 88, 141-153.

Kaçar C, Yıldız S, Pancarcı ŞM, Kaya M, Güngör Ö, Arı UÇ, 2007: Effect of administration of lesireline five days after artificial Insemination on pregnancy rates and luteal function in cows. Kafkas Üniv Vet Fak Derg, 13(2), 139-142.

Kaim M, Bloch A, Wolfenson D, Braw-Tal R, Rosenberg M, Voet $H$, Folman Y, 2003: Effects of GnRH administered to cows at the onset of estrus on timing ofovulation, endocrine responses, and conception. J Dairy Sci, 86, 2012-2021.

Lee CN, Critser JK, Ax RL, Folman Y, 1985: Changes of luteinizing hormone and progesterone for dairy cows after gonadotropin-releasing hormone at first postpartum breeding. J Dairy Sci, 68, 1463-1470.

Lee $\mathrm{CN}$, Maurice E, Ax RL, Pennington JA, Hoffman WF, Brown MD, 1983: Efficacy of gonadotropinreleasing hormone administered at the time of artificial insemination of heifers and postpartum and repeat breeder dairy cows. American J Vet Res, 44, 21602163.

Lopez-Gatius F, Santolaria P, Martino A, Deletang F, Rensis FD, 2006: The effects of GnRH treatment at the time of $\mathrm{Al}$ and 12 days later on reproductive performance of high producing dairy cows during the warm seasonin northeastern Spain. Theriogenology, 65, 820-830.

Martin R, Schmausser M, Seidl S, Schmauder S, Mansfeld $R$, 2005: Use of Lecirelin to improve insemination efficiency of dairy cattle. Praktısche Tierarzt, 86(12), 914-919.

Mee MO, Stevenson JS, Scoby RK, 1990: Influence of gonadotropin-releasing hormone and timing of insemination relative to estrus on pregnancy rates of dairy cattle at first service. J Dairy Sci, 73, 15001507.

Millar RP, 2005: GnRHs and GnRH receptors. Anim Reprod Sci, 88, 5-28.

Momcilovic D, Archbald LF, Walters A, Tran T, Kelbert D, Risco C, Thatcher WW, 1998: Reproductive performance of lactating dairy cows treated with gonadotrophin-releasing hormone $(\mathrm{GnRH})$ and/or prostaglandin F2 $\alpha$ (PGF2 $\alpha$ ) for synchronization of estrus and ovulation. Theriogenology, 50(7), 11311139.

Nakao T, Narita S, Tanaka K, Hara, H, Shirakawa J, Noshiro H, Saga N, Tsunoda N, Kawata K, 1983: Improvement of first-service pregnancy rate in cows with gonadotropin-releasing hormone analog. Theriogenology, 20, 111-119.

Padula AM, 2005: GnRH analogues-agonists antantagonists. Anim Reprod Sci 88: 115-126.

Perry GA, Perry BL, 2009: GnRH treatment at artificial insemination in beef cattle fails to increase plasma progesterone concentrations or pregnancy rates. Theriogenology, 71, 775-779

Rizzo A, Minoia G, Trisolini C, Mutinati M, Spedicato M, Manca R, Sciorsci R, 2009: Renin and ovarian vascularization in cows with follicular cysts after epidural administration of a GnRH analogue. Anim Reprod Sci, 116, 226-232. 
Rizzo A, Spedicato M, Mutinati M, Minoia G, Pantaleo, M, Sciorsci RL, 2011: In vivoand in vitrostudies of the role of the adrenergic system and follicular wall contractility in the pathogenesis and resolution of bovine follicular cysts. Theriogenology. 76, 15261531.

Robbe D, D'Ottavio M, Sciorsci RL, 2002: Terapia della cisti follicolari della bovina. Obiettivi e Documenti Veterinari (O. D. V), 7/8, 19-24.

Scheiber MD, Liu JH, 2014: The use of GonadotropinReleasing Hormone to induce ovulation. https://www.glowm.com/.../cd/.../v5c071.html, Erişim tarihi; 30.10.2014.

Schneider F, Tomek W, Gründker C, 2006: Gonadotropinreleasing hormone $(\mathrm{GnRH})$ and its natural analogues: A review. Theriogenology, 66, 691-709.

Singh R, Graves ML, Roskelley CD, Giritharan G, Rajamahendran R, 2008: Gonadotropin releasing hormone receptor gene and protein expression and immunohistochemical localization in bovine uterus and oviducts. Dom Anim Endocrin, 34, 319-326.

Stevenson JS, Schmidt MK, Call EP, 1984: Gonadotropinreleasing hormone and conception of Holsteins. J Dairy Sci, 67, 140-145.

Şekerden Ö, Uraz H, Söğüt Ö, 2009: Kilis ineklerinde kan progesteron testi kullanılarak erken gebelik teşhis imkanları. Hayvansal Üretim, 50(2), 29-32.

Üstün Z, 2011: Sıcak stresi altındaki süt ineklerinde tohumlama protokolü sonrası epidural $\mathrm{GnRH}$ uygulamasının gebelik oranı üzerine etkisi. Yüksek lisans tezi, Adnan Menderes Üniversitesi Sağlık Bilimleri Enstitüsü, Aydın.

*Yazışma Adresi: Hamit YILDIZ

Fırat Üniversitesi Veteriner Fakültesi Doğum ve Jinekoloji Anabilim Dalı, Elazı ğ, Türkiye.

e-mail: hamityildiz@firat.edu.tr 